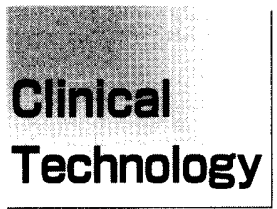

Received Jan. 28, 2005

Revision accepted April 27, 2005

Code No. 261

\section{High-resolution MRI of the Labyrinth: Optimization of Scan Parameters with 3D-FSE}

\author{
MOTOMICHI SAKATA, KUNIAKI HARADA,1) RYUJI SHIRASE, ${ }^{1)}$ \\ AKIKO KUMAGAI, ${ }^{1)}$ and MASASHI OGASAWARA ${ }^{1)}$
}

\begin{abstract}
Sapporo Medical University Graduate School of Medicine. Molecular and Organ Regulation. Division of Organ Function and Therapeutics, Radiation Oncology, Imaging, and Diagnosis

1 ) Sapporo Medical University Hospital Division of Radiology and Nuclear Medicine
\end{abstract}

\section{Introduction}

Magnetic resonance imaging (MRI) is increasingly being used in the examination of patients with sensorineural hearing loss. ${ }^{1}$ Several MRI units with a 3D fast spin-echo (3D-FSE) sequence for high-resolution MRI of the labyrinth have been introduced. However, the sequence has not yet been optimized for each MRI unit. Our ultimate goal is to select and optimize the parameters of the 3D-FSE sequence for visualization of important anatomic details in high-resolution MRI of the labyrinth.

\section{Materials and Methods}

All imaging was performed with 1.5 Tesla MR unit (Signa LX, GE Medical Systems, Milwaukee, WI, USA). The contrast-to-noise ratio (CNR) and the signal-to-noise ratio (SNR) between the cochlea (basal turn and apical turn) and the tympanic cavity including ossicles were measured three times at the level of the cochlea's basal turn and apical turn. The scan parameters below were varied to determine the optimal values. A healthy volunteer (48-year-old man) was selected to determine the optimal parameters. A phantom(TLT HEAD SPHERE NICL2, model 46-265826G6, $\Phi 17 \mathrm{~cm}$, GE Medical Systems, Milwaukee, WI, USA) was used for coil selection.

Effective TE was set to 50, 100, 150, 200, 250, 300, 400 , and $500 \mathrm{~ms}$, with TR set to $5000 \mathrm{~ms}$. TR was set to 2000, 3000, 4000, 5000, 6000, and $7000 \mathrm{~ms}$, with TE set to $300 \mathrm{~ms}$. With TR set to $5000 \mathrm{~ms}$ and TE set to $300 \mathrm{~ms}$, the matrix was set to $128 \times 128$ and $256 \times 256$; the number of excitations (NEX) was set to 1, 2, and 3; the field of view (FOV) was set to $12 \mathrm{~cm} \times 12 \mathrm{~cm}$ and 16

\title{
Summary
}

The aim of our study was to optimize the parameters of high-resolution MRI of the labyrinth with a 3D-FSE sequence. We investigated TR, TE, Matrix, FOV, and coil selection in terms of CNR (contrast-tonoise ratio) and SNR (signal-to-noise ratio) by comparing axial images and/or three-dimensional images. The optimal 3D-FSE sequence parameters were as follows: 1.5 Tesla MR unit(Signa LX, GE Medical Systems), 3D-FSE sequence, dual 3-inch surface coil, acquisition time $=12.08 \mathrm{~min}$., TR=5000 $\mathrm{msec}, \mathrm{TE}=300 \mathrm{msec}, 3$ NEX, FOV=12 cm, matrix $=256 \times 256$, slice thickness $=0.5 \mathrm{~mm} / 0.0 \mathrm{sp}$, echo train=64, bandwidth= $\pm 31.5 \mathrm{kHz}$. High-resolution MRI of the labyrinth using the optimized 3D-FSE sequence parameters permits visualization of important anatomic details (such as scala tympani and scala vestibuli), making it possible to determine inner ear anomalies and the patency of cochlear turns. To obtain excellent heavily T2-weighted axial and three-dimensional images in the labyrinth, high CNR, SNR, and spatial resolution are significant factors at the present time. Furthermore, it is important not only to optimize the scan parameters of 3D-FSE but also to select an appropriate coil for high-resolution MRI of the labyrinth.

Tey words: High-resolution MRI, Labyrinth, 3D-FSE, Scan parameters

別刷資料請求先：テ060-8556 札幌市中央区南1条西17丁目

柇幌医科大学医学部大学院医学研究科 分子. 器官制御医学専攻 器官機能治療学領域 放射線治療診断学 坂田元道 宛 
$\mathrm{cm} \times 16 \mathrm{~cm}$, with or without options (flow compensation, fat saturation). Other parameters were selected as follows: slice thickness was $0.5 \mathrm{~mm}$ with no gap, echo train was 64 , and bandwidth was $\pm 31.5 \mathrm{kHz}$. All images were obtained by using a dual 3 -inch surface coil. Furthermore, FOV, NEX, and matrix were also evaluated by the quantitative comparison of axial images and three-dimensional images.

A head coil, the QHNV (Quadrature Head \& Neck Vascular) coil, 5-inch dual surface coil, and 3-inch dual surface coil were tested to select a suitable coil under the optimized parameters of the 3D-FSE sequence for high-resolution MRI of the labyrinth.

For the quantitative evaluation of mean SNR and CNR, regions of interest (ROI) were measured from the cochlear apical and basal turns and from the background (the region of the ossicles and tympanic cavity). The signal-to-noise ratio (SNR) was calculated as the ratio of the mean signal intensity within the cochlear turns to the standard deviation of the background signal intensity. The contrast-to-noise ratio $(\mathrm{CNR})$ was defined as the difference in mean signal intensity between the cochlear turns and the background divided by the standard deviation of noise. ${ }^{2)}$ The numbers of excitations (NEX) and coil selections were also assessed by CNR and SNR. In addition, five experienced radiological technologists assessed axial images and three-dimensional reconstructions to evaluate matrix and FOV. Image quality was scored on a simple subjective scale as $1=$ poor, $2=$ acceptable, and $3=$ good.

Axial images were transferred to an independent workstation(GE Advantage Windows 3.1, Sun Micro- systems, SPARC 20), and three-dimensional imaging with volume rendering was carried out.

\section{Results}

The maximum CNR and SNR were obtained at TR $5000 \mathrm{~ms}$, TE $300 \mathrm{~ms}$ (Figs. 1 and 2), and NEX of 3 (data not shown). For selection of the matrix and FOV, the matrix set to $256 \times 256$ and FOV set to $12 \mathrm{~cm}$ of image quality were superior to the matrix set to $128 \times 128$ and FOV set to $16 \mathrm{~cm}$ (data not shown). For three-dimensional imaging especially, setting the matrix to $256 \times 256$ and FOV to $12 \mathrm{~cm}$ clearly depicted all cochlear turns (Figs. 3 and 4). The options (flow compensation, fat saturation) were not necessary as a result of increasing CNR and SNR (data not shown). The sensitivity profiles of all coils are described Fig. 5. The maximum CNR and SNR of images were obtained by a dual 3 -inch circular surface coil (Fig. 6).

As the final results, the selected, optimized sequence parameters were as follows: dual 3-inch circular surface coil, TR=5000 msec, TE=300 msec, 3 NEX, FOV=12 $\mathrm{cm} \times 12 \mathrm{~cm}$, matrix $256 \times 256$, slice thickness, $0.5 \mathrm{~mm} / 0.0$ sp, echo train $=64$, bandwidth $= \pm 31.5 \mathrm{kHz}$. The options were not necessary. The acquisition time was $12 \mathrm{~min}$ utes, 8 seconds. Axial and three-dimensional images were obtained by using the above parameters (shown in Figs. 7 and 8 ).

\section{Discussion}

In comparison with other MR units, ${ }^{3-7)}$ the scan parameters were almost the same as our results. It is important to obtain both high-quality and same-quality

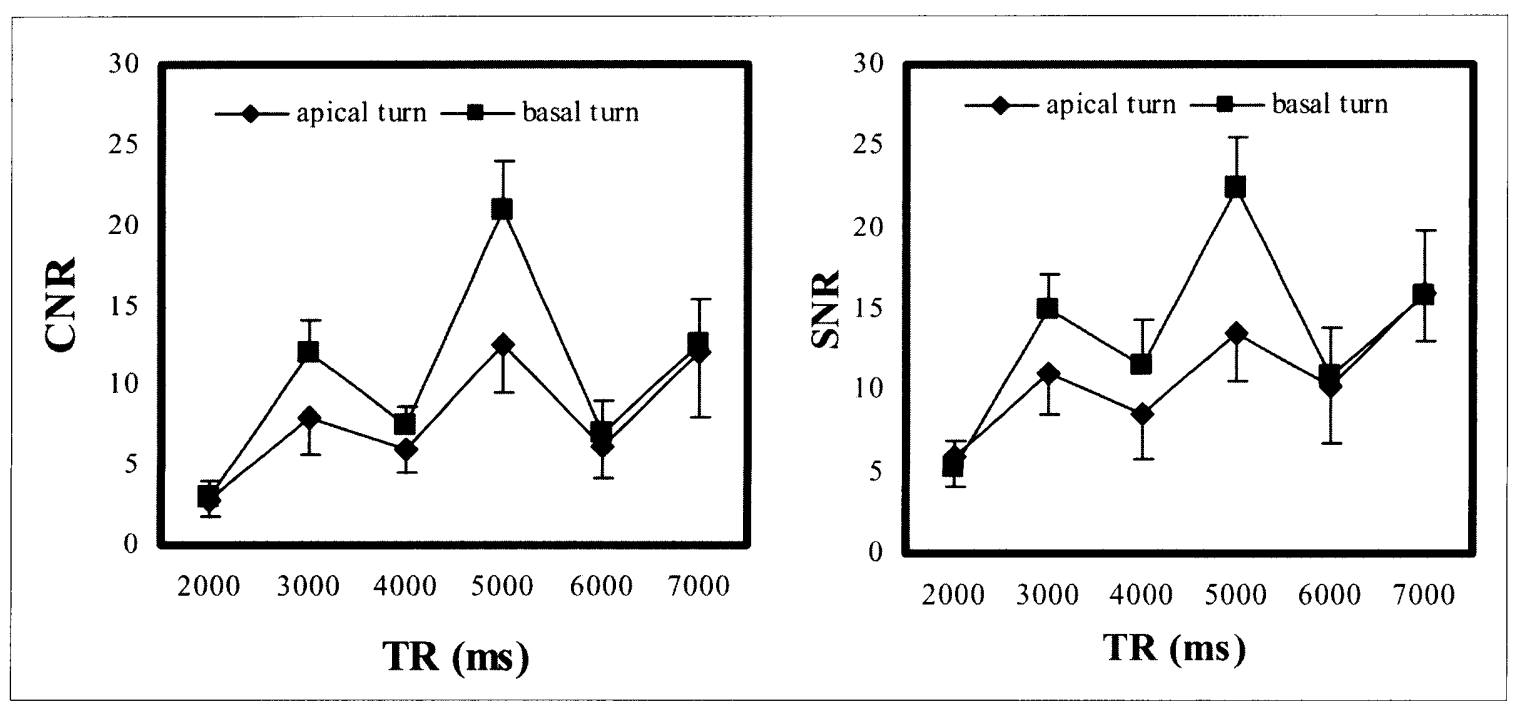

Fig. 1 Contrast-to-noise ratio, signal-to-noise ratio with TE set to $300 \mathrm{~ms}$ at various TR values. 

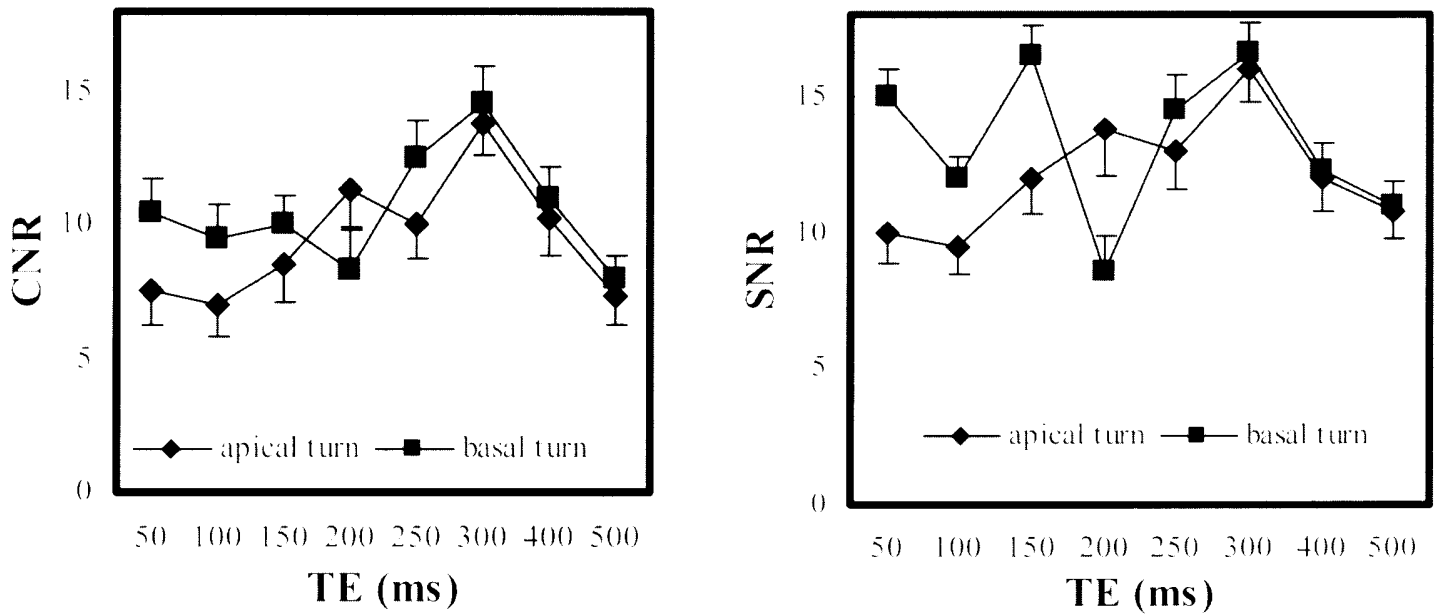

Fig. 2 Contrast-to-noise ratio, signal-to-noise ratio with TR set to $5000 \mathrm{~ms}$ at various TE values.

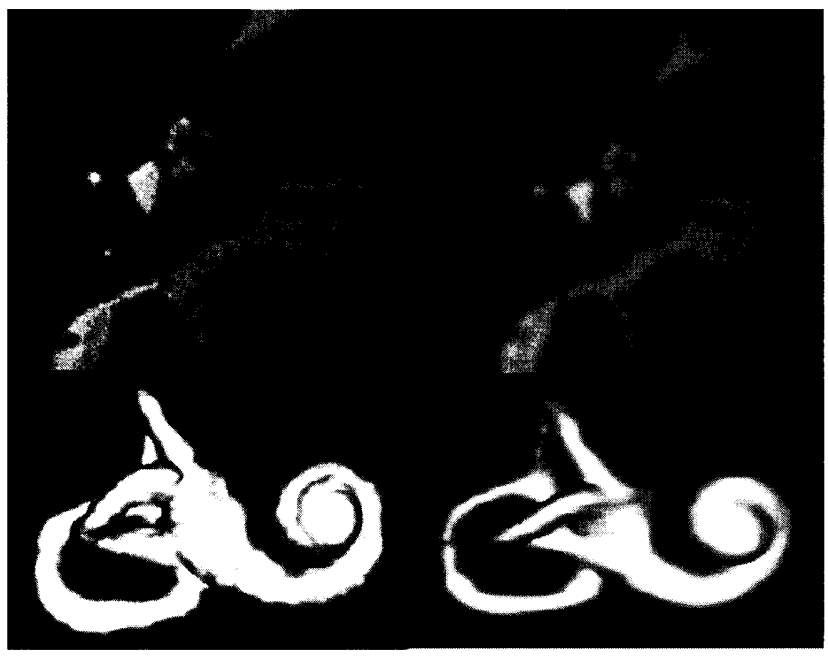

Fig. 3 Axial and three-dimensional images at two different matrices. (a), (b) $256 \times 256$, (c), (d) $128 \times 128$.

MRI throughout the world. It is ckat that high-quality axial and three-dimensional images reflect the parameters of the original data. Hence, we determined the optimized 3D-FSE seyuence and coil selection. Thus. these assessments could be valuable for all MR examinations and equipment. Moreover, three-dimensional images (virtual endoscopy and/or volume rendering) could be uscful for cochlear implantation candidates.

In a comparative study. Lane et al." reported that banding artilates were problematic with the CISS constructive interference in steaty state technique. Becatuse of this susceptibility. fine structures of the labyrinth such as the cochlear fluid channels and semicircular canals maly appear imegular as compared with the 3D-FSI sequence. Hans et al.' have reported that use

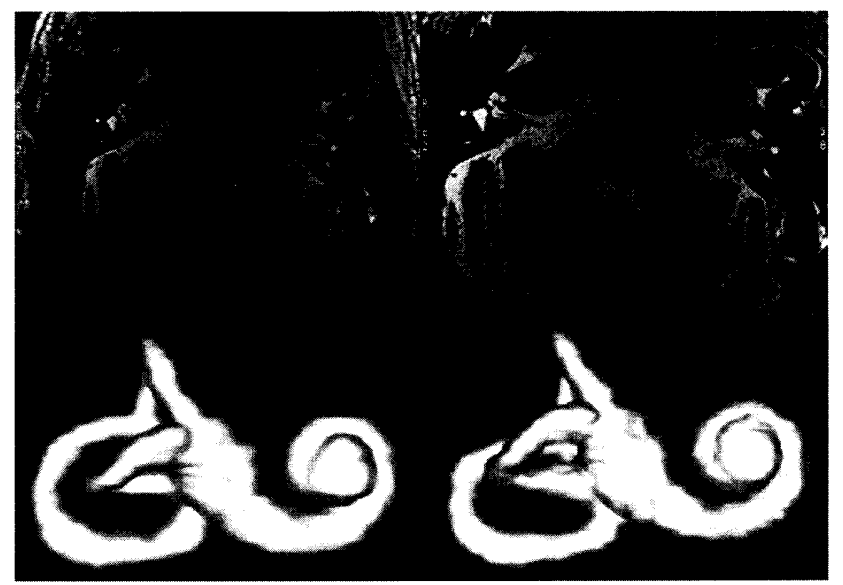

Fig. 4 Axial and three-dimensional images at two different fields of view. (a), (b) $16 \mathrm{~cm}$, (c), (d) $12 \mathrm{~cm}$.

a c

b d

of the FSE technique reduced susceptibility artifacts and resulted in maintenance of true $\mathrm{T} 2$ contrast rather than the $\mathrm{T} 2$ * contrast characteristics of gradient-echo methods.

The purposes of high-resolution MRI of the labyrinth are to demonstrate fine labyrinthine structures including the scala tympani (ST), scala vestibuli SV . cochlear duct $(C D)$, tectorial membrane, and Reissner"s membrane. These fine structures are demonstrated by the highest spatial resolution matrix. FOV. slice thickness), CNR, and SNR. Slice thickness and matrix are more important factors in spatial resolution. $\mathrm{A}$ 3-Tesla MR scanner is able to improve the CNR, SNR. and spatial resolution. ${ }^{7-9}$ Graf et al." mentioned that the SNR at 3 Tesla was, on average, a factor of 1.34 higher 


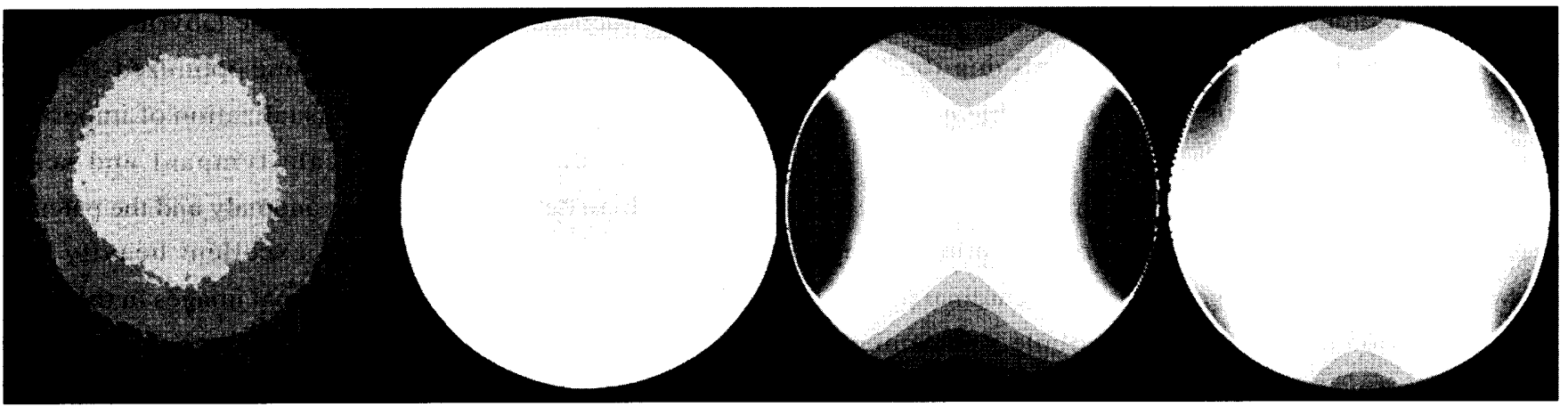

Fig. 5 Various coil-sensitivity profiles.

(a) Head, (b) QHNV, (c)3-inch surface, (d) 5-inch surface.
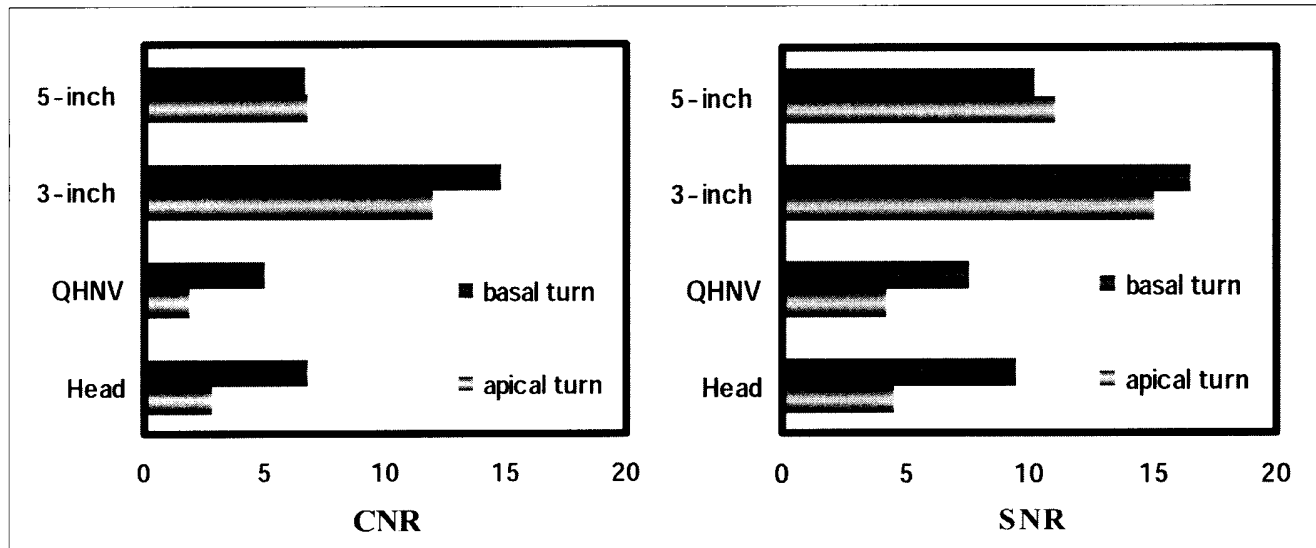

Fig. 6 Contrast-to-noise ratio and signal-to-noise ratio for various coils.

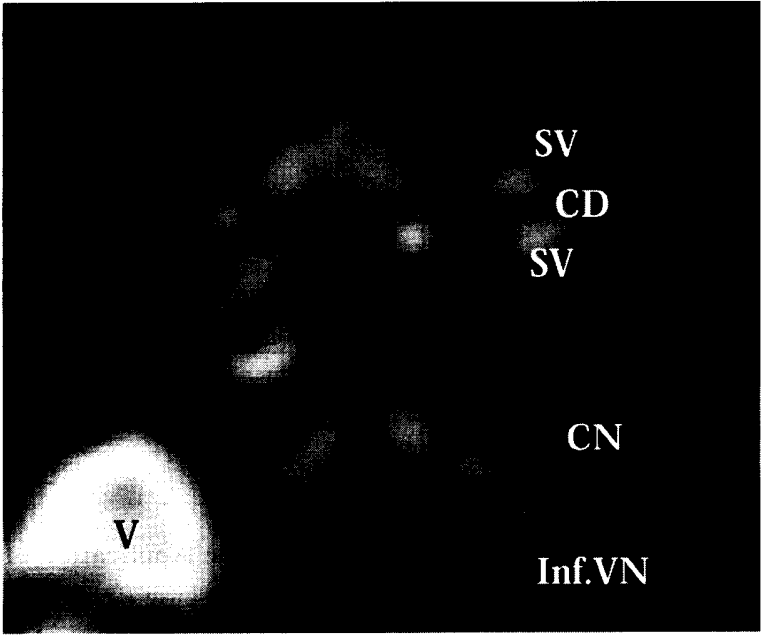

Fig. 7 Axial normal anatomy of the labyrinth. Images obtained by using optimized parameters. SV: scala vestibuli, CD: cochlear duct, ST: scala tympani, CN: cochlear nerve, Inf. V: inferior vestibular nerve, $\mathrm{V}$ : vestibule.

than that at 1.5 Tesla. Moreover, the development of surface coils desired for the labyrinth is also important. ${ }^{7)}$ Surface coils are usually used only as receiver coils. With the development of an intra-canalicular (similar to a hearing aid) receiver coil, CNR, SNR, and spatial resolution may be increased.

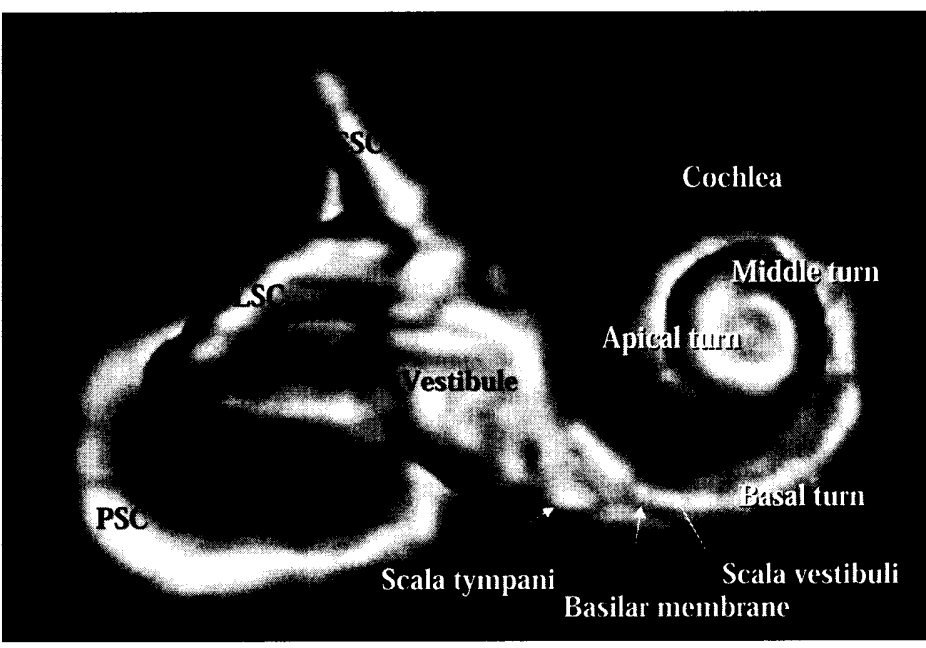

Fig. 8 Three-dimensional normal anatomy of the labyrinth. Images obtained by using optimized parameters. SSC: superior semicircular canal, PSC: posterior semicircular canal, LSC: lateral semicircular canal.

The number of excitations is associated with increases in the values of CNR, SNR, and acquisition time. Recently, cochlear implants have tended to be utilized for young children. Hence, young cochlear implant candidates require sedation and a short acquisition time in the MR examination. The relationship between the 
number of excitations and acquisition time presents a trade-off. We should be flexible in defining the optimal number of excitations for young cochlear implant candidates.

Finally, the fundamental scan protocols for highresolution MRI of the labyrinth were determined using T1-weighted localizer images in the three cardinal planes, and the position of the cochlea, vestibule, and semicircular canals was identified using a series of 3-mm-thick coronal $\mathrm{T} 2$-weighted fast spin-echo images. Imaging of the labyrinth was performed using a dual 3-inch circular surface coil positioned over the external auditory canal. A series of heavily T2-weighted images was then obtained by optimized 3D-FSE sequences in the axial plane.

\section{Conclusion}

The results of our study determined optimized 3D-
FSE sequences for demonstrating the labyrinth. Highresolution MRI of the labyrinth using optimized 3D-FSE sequence parameters permits visualization of important anatomic details (such as scala tympani and scala vestibuli) to determine inner ear anomaly and the patency of cochlear turns. To obtain excellent heavily T2weighted axial and three-dimensional images in the labyrinth, high CNR, SNR, and spatial resolution are significant factors at the present time. Furthermore, it is important not only to decide the scan parameters of 3DFSE but also to select the coil for high-resolution MRI of the labyrinth.

\section{Acknowledgments}

The authors thank Hirotada Fujii, Ph.D., and Masato Hareyama, M.D., Ph.D., for their valuable comments on earlier versions of this paper.

\section{References}

1) Hans P, Grant AJ, Laitt RD, et al.: Comparison of ThreeDimensional Visualization Techniques for Depicting the Scala Vestibuli and Scala Tympani of the Cochlea by Using HighResolution MR Imaging. Am J Neuroradiol, 20 (7), 1197-1206, (1999).

2) Wolff SD, and Balaban RS: Assessing contrast on MR images. Radiology, 202(1), 25-29, (1997).

3) Naganawa $S$, Iwayama E, Koshikawa T, et al.: Virtual Endoscopy of the Labyrinth, Using a 3D-FastASE Sequence. J Mag Res Imag, 13 (5), 792-796,(2001).

4) Diamantopoulus II, Ludman CN, Martel AL, et al.: Magnetic Resonance Imaging Virtual Endoscopy of the Labyrinth. Am J Otol, 20 (6), 748-751,(1999).

5) Neri E, Caramella D, Cosottini M, et al.: High-resolution magnetic resonance and volume rendering of the labyrinth. Euro Radiol, 10(1), 114-118,(2000).
6) Murugasu E, Hans P, Jackson A, et al.: The Application of Three-Dimensional Magnetic Resonance Imaging Rendering of the Inner Ear in Assessment for Cochlear Implantation. Am J Otol, 20 (6), 752-757,(1999).

7) Naganawa S, Koshikawa T, Fukatsu H, et al.: Fast Recovery 3D Fast Spin-Echo MR Imaging of the Inner Ear at 3T. Am J Neuroradiol, 23 (2), 299-302,(2002).

8) Lane JI, Ward H, Witte RJ, et al.: 3-T Imaging of the Cochlear Nerve and Labyrinth in Cochlear-Implant Candidates: 3D Fast Recovery Fast Spin-Echo versus 3D Constructive Interference in the Steady State Techniques. Am J Neuroradiol, 25 (4), 618-622,(2004).

9) Graf H, Schick F, Claussen CD, et al.: MR Visualization of the Inner Ear Structures: Comparison of 1.5 Tesla and 3 Tesla Images. Rofo, 176(1), 17-20,(2004). 
Fig. 1 TE：300msにおけるTRの変化に対するCNRおよびSNR

Fig. 2 TR：5000msにおけるTEの変化に対するCNRおよびSNR

Fig. 32 種類のマトリックスにおけるaxial像と三次元画像

(a), (b) $256 \times 256$, (c), (d) $128 \times 128$

Fig. 42 種類のFOVにおけるaxial像と三次元画像

(a), (b) $16 \mathrm{~cm}, \quad$ (c), (d) $12 \mathrm{~cm}$

Fig. 54 種類のコイルの感度表示

(a) Head, (b) QHNV, (c) 3-inch surface, (d) 5-inch surface

Fig. 64 種類のコイルのCNR, SNR

Fig. 7 迷路の正常解剖 (axial像)

$\mathrm{SV}$ : 前庭階, $\mathrm{CD}$ : 蝸牛管, $\mathrm{ST}$ : 鼓室階, $\mathrm{CN}$ : 螖牛神経, Inf. $\mathrm{V}$ : 下前庭神経, $\mathrm{V}$ : 前庭

Fig. 8 迷路の正常解剖 (三次元画像)

SSC：上半規管, PSC : 後半規管, LSC：側半規管 